\title{
Simulated Decision Learning in a Multiactor Setting
}

\author{
Viveca Asproth, Stig C Holmberg, and Ulrica Löfstedt
}

ITM / Informatics, Mid Sweden University, 83125 ÖSTERSUND, Sweden, (viveca.asproth, stig.holmberg, ulrica.lofstedt)@miun.se

\begin{abstract}
The idea of decision analysis - and subsequent learning from the outcomes - is old within Operational Research. Here this approach to continuous improvement of decision outcomes is put one step further within the area of crisis and disaster management. This is done by introducing multiactors making simultaneous decisions with just partial information about each other. Further, decision outcomes are achieved from a simulation model rather than from the real object system.
\end{abstract}

Keywords: Multi Layered Systems, Anticipation, Retardation, Learning, Simulation.

\section{Introduction}

As manifested in the European FP7 research program, Security has lately become a main issue in European Research and Technical Development ${ }^{1}$ (RTD). This broad area includes, among many other topics, research on simulation, planning, and training tools for management of crisis and complex emergencies. The rationale for that focus may be found in current research. In short, those recent research results indicate that the outcome of an emergency situation to a large extent is due to the preparations and trainings done before the crisis or disaster outbreak (Bolin and Hart, 2007). Those current research insights, however, is still just to a tiny bit transformed into operational training tools.

Hence, this paper will demonstrate and discuss the design of the netAgora crisis simulation and training environment. It is a solution both meeting the requirements of a recent $\mathrm{FP}^{2}$ call and building on current research results.

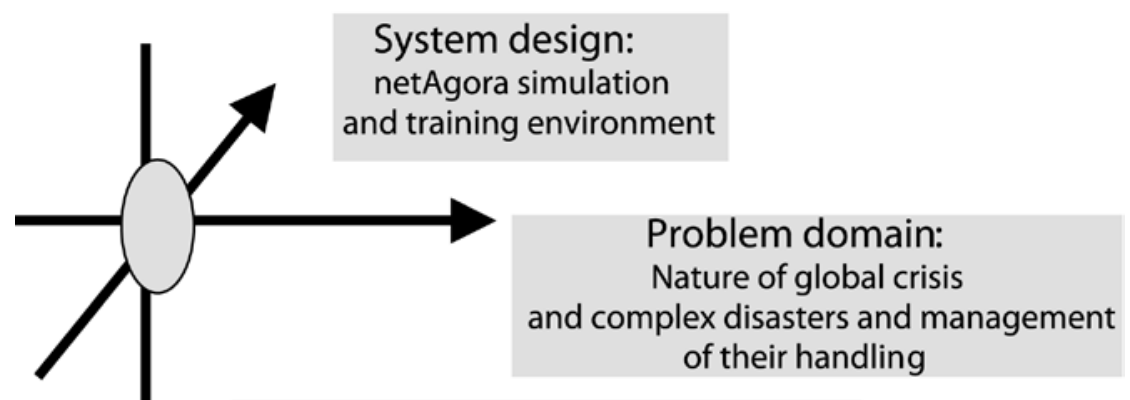

Solution arsenal:

Modelling and simulation,

$\mathrm{KM}$, web technique, decision support, communication, design, etc.....

Figure 1. Integration of problem domain insights and solution arsenal competencies.

$1 \mathrm{http} / / /$ cordis.europa.eu/fp7/dc/index.cfm

2 Call identifier: FP7-SEC-2009-1, Date of publication: 3 September 2008 
The purpose of this paper, hence, being to increase the understanding of proper facilities for crisis and disaster training and preparation. The solution put forward here applies systems thinking and a multi modal system design methodology in order to solve a practical operational planning problem. This approach will integrate research insights from both social and engineering (technological) sciences.

\section{Research approach}

In the quest for the netAgora research objective, systems science and multi methodology will constitute the epistemological base. From that base an experimental and prototyping process will be applied toward the project goal. The meaning of this approach will in some detail be discussed with help of Figure 1.

In Figure 1 the horizontal, problem domain, axis is the primary, steering or predominant one. It points toward the part of the real world that ought to changed by netAgora's deliberate actions. In the actual case, this mean training and preparation facilities for global crisis and complex disaster situations.

Whatever method and technique that may be used, however, it is just the impact in the problem domain that will be the measure of success or failure. Hence starting on the horizontal axis, a broad survey of current research results from the social sciences will be performed. That will give an understanding of netAgora's part of the problem domain and its specific requirements. Those identified requirements will then work as the target for the rest of the netAgora process.

Coming to the vertical axis, i.e. the solution arsenal, here are all the methods, techniques, and tools that can be useful in providing the best possible solution for the problem domain items in focus. Here netAgora identify its task as an application of Operational Research (OR) with its specific challenges and problems (Holmberg, 2001). However, as Keys (1991) has identified close and obvious relations between OR and systemics, it is found that the solution mainly ought to be created with help of systems thinking and systemic methodologies. Leleur (2005) has on this point demonstrated how the highly theoretical thinking of Habermas and Luhmann can be applied in a pragmatic way in working with complex inter national projects.

As the problem domain in focus is highly complex and exposes all aspects of human life netAgora chooses the much inclusive Living Systems Theory (Miller, 1978) as a general framework. Albeit it is a representative for the somewhat outdated Functionalist Systems Approach Holmberg (2008) has demonstrated that Living Systems Theory has a great potential for further development and symbiotic combinations with other methods and theories. This is fully in line with the Multi Methodology approach advocated by Mingers and Gill (1997) and others.

Our working methodology will closely follow Idealized Design according to Ackoff et al (2006). This well proven design methodology has already been used with good results on several occasions (Holmberg, 2001). Other design input comes from Warfield's (1990) Generic Design and Banathy's (1996) third generation's Social Systems Design.

For the technical tools, at last, netAgora will use web services not only for providing information but even more for encouraging participation and empowerment (Nyström, 2006). Implementation of codesign, according to the vision of third generation design (Banathy, 1996), may also be within reach with help of web technology (Löfstedt, 2008).

A simulation technique, which is simple and straightforward to distribute over intranet to ordinary users without any specific simulation skills, have been demonstrated by Dubois and Holmberg (2008) and will be applied also here. Geographical or spatial information, which is crucial in this type of applications, will be handled with a fuzzy approach (Asproth et al., 2006).

Hence, by integrating all that have been discussed so far in a design process, the solution will emerge along the third and last axis in Figure 1. This result will be the design for the netAgora simulation and training environment.

\section{Project control}

With the epistemological and methodological principles established the project has to involve and enhance cooperation between several European universities together with major organisations and industry firms from the specific area of emergency and disaster management. With this broad EU partner base the project is divided into seven distinct work packages and with three to five partners cooperating in each of them.

NetAgora, as seen in Figure 2, departures from two launching points in its first work package (WP1). Those are first the needs, wishes, and requirements of netAgora's future users. The second is the existing stock of open source tools and development environments. With this platform established it is the responsibility of WP2 - WP4 to design and construct both a set of test scenarios and the netAgora environment with its disaster simulator and other training tools. With a first version of netAgora environment up and running, verification and improvements will be done in WP5 - WP6. Here true users from different user categories will run the disaster simulator and environment with the different test scenarios. Tho evaluation results from those tests will finally be used in correcting faults and in improving the tools.

During the predicted project time of 40 months great effort should be put into management and coordination of the project (WP0). As the project should involve researchers and developers from both social and technological sciences together with a great number of normal users from different cultural milieus, this complex WP will require both finesse and high attention.

Dissemination (WP7), at last, is the interface towards European security actors at large. Through this activity the project results are put to the benefit of European citizens and European firms working within the security sector. The distribution of those phases or work packages is shown in Figure 2. 


\section{Project Management (WP0)}
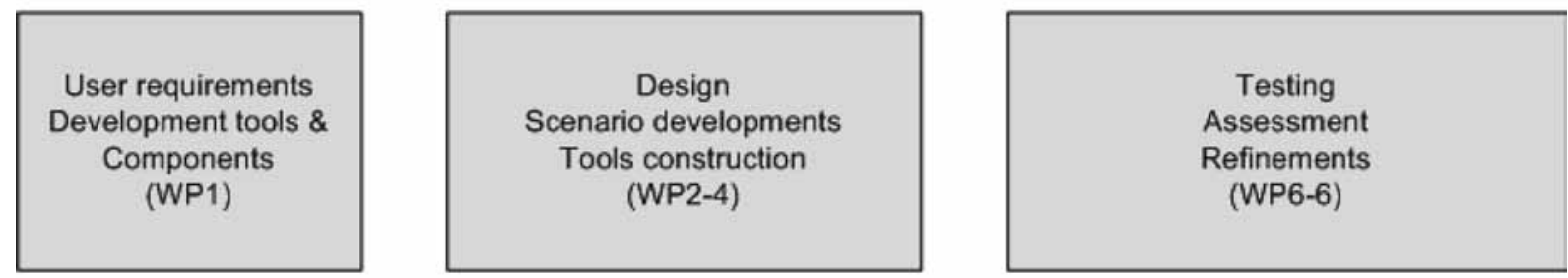

Dissemination (WP/7)

\section{Current research and steps beyond}

The systematic social science study of disasters has only been present for half a century and social science knowledge for dealing with disasters is hence a rather recent phenomenon (Quarantelli, 1988; 2000). Here Boin and 't Hart (2007) claim that a mix of perspectives is needed to understand the complexities and dynamics of crisis and crisis management. Quarantelli et al. (2007) further claim that the area of disasters and crisis is changing and new types of risks and hazards as well as changes in social settings are emerging.

Published research indicates that the final outcome of a disaster is highly dependent on early preparations and training made before the crisis outbreak (Sundelius et al., 2001). Boin and 't Hart (2007) here argue that earlier crisis offers a good learning source for feasible planning and preparations for future ones. However, the capability of organizations to adjust to new conditions and policies is limited, and some researchers even claim that collective learning is not possible in complex organizations (Perrow, 1999).

Simulation and scenarios can be used to achieve organizational learning and research in this area (Burt \& Chermack, 2008; Kljajić et al., 2007; Ekker \& Eidsmo, 2006). Multi disciplinary based knowledge is, however, critical to accomplish simulation models and scenarios as realistic tools for emergency planning and intervention. Santos and Aguirre (2004: 44) writes: “...research and theory in the social sciences can have an important effect in grounding the models in realistic assumptions regarding social behaviour in crisis situations, and such modelling in turn could enrich our understanding of collective behaviour in crisis situations". Also theories of sense making and trust in and between organizations, and earlier research of crisis management and organizational learning (e.g. Asproth, 2007; Asproth \& Håkansson, 2007; Asproth \& Nyström, 2008), will be of interest for further research in this area.

The process oriented emergency management approach addresses the crucial issue of different understandings of the emergency situation. Today emergency training and simulation tools assume that involved organizations and individuals have the same image, or view, of the emergency site/situation, although empirical evidence indicate differently (Alvinius et al., 2007; Danielsson et al., 2007). Different organizations, as well as individuals within organizations, understand the situation differently depending on their task, position, information, knowledge, organizational culture and preparedness for action. The concept of sense making has proved to be useful for understanding this phenomenon (Weick, 1998; 2005). It can be understood as a process of placing stimuli or phenomena into context or a framework (e.g. organizational culture). There are few studies of how emergency management works at an international emergency site with actors not only representing different kinds of rescue agencies, public and private organizations and volunteers, but also different countries. However, the need to train and educate emergency agencies in handling such situations is vital.

McEntire (2007) has explored what is known about official and unofficial participants in emergency management at the community. The actors can be of different types (e.g. human beings, organisations, rescue teams etc. and it can be stated that there are many types of actors involved in a disaster.

Social scientific research has repeatedly showed that emergencies are characterized by complexity, dynamic but 
rational behaviour, and that models based on continuity, coordination, cooperation, process and improvisation are more adequate than traditional rigid views on involved organizations and the emergency process (e.g. Alvinius et al., 2007; Rodrígues et al., 2006; Olofsson, Öhman \& Rashid, 2006; Wachtendorf \& Kendra, 2006). Still, emergency management, and related fields e.g. crisis communication, emergency organizational learning, training and simulation, are generally handled and studied as an intra, rather than an inter, organizational phenomenon (Danielsson et al., 2007; Fearn-Banks, 2002; Gordon, 2008; Olofsson, 2007).

Also organizational cooperation is mandatory in all kind of emergencies and current trends indicate that the future brings challenges to involve a wider range of actors from different regions and countries, i.e. demanding more complex collaborations (e.g. Caruson \& MacManus, 2008; Quarantelli, 2006).

Disasters create a large number of victims, disable transportation systems, and place excessive demands on first responders, i.e. ordinary citizens who happen to be on the disaster location. Many important and urgent postdisaster needs cannot be addressed quickly or adequately by the official rescue organisations. Hence, bystanders and victims do not simply wait for any rescue team to show up. They take initiative to care for themselves and for others. Research has consistently shown that citizens engage in emergency response after a disaster (Drabek \& McEntire, 2002).

Research has also shown that the human desire to help those in need is nearly an incontestable fact in nearly every type of disaster. People join together to complete tasks that often include rescue of victims. According to Dynes (1970) emergent groups are different than other types of organisations. Stallings and Quarantelli (1985) claim that these groups undertake activities that were previously foreign to them and develop a social structure that lacks formalization, tradition, and endurance. In contrast, an established organization performs routine functions in a disaster and maintains its traditional organizational relationship with the chief and subordinates.

Poteyeva et al. (2007) further claim the need for an international program of public education on first aid and emergency medicine. Such a program also ought to teach people what to do if they become and how to work as first responders.

Accordingly first responders are crucial in disaster management and the information to the public, i.e. the citizens are of great importance. Drabek (2007) even claims that future research ought to develop a theory of disaster response and emergency management.

The acceptance and application of earlier research results, however, must be made with some reservations. This since even if many important insights have been gained concerning disasters and crisis management there are still numerous questions of paramount importance remaining to be answered. Further, several of the results quoted here are, at least apparently, contradictory and a great part of them have not yet been field tested and verified in practical disaster work. With that said, the development of NetAgora system work here will build on the following compilation of current research insights:

- Final outcome of a disaster is highly due to preparations and training

- Many types of actors with different skills and cultures will be involved during rescue and recovery

- Communication and Coordination will be more important than Command and Control

- First responders are of paramount importance in rescue work

- The quality of information to the public (citizens) will be a crucial factor

A last observation of a more epistemological nature may be that most of the cited researchers apply a mono methodological approach, each advocating their specific research approach as the best and only successful one. Despite that, the netAgora endeavour will stick to a systems based multi methodology.

\section{The netAgora environment}

In trying both taking care of current research insights and meeting the requirements of the FP7 call we here propose the development of the netAgora environment. Hence, within the netAgora project a computer and net based integrated environment for mutual preparation and training for disasters and complex emergency situations should be developed. The netAgora environment will be all comprehensive with a disaster simulator, a scenario editor, and an assessment kit included in its core. It will support cooperation, coordination, training, preparation, and learning on individual, group, and organisational levels. The netAgora should further include support for an exchange of experiences, tools, and models of response to emergence situations within and between nations with a special emphasis on handling the cultural differences that may impede the emergence response.

Main components in netAgora are shown in Figure 3. The Virtual Situation Room (VSR) is the interaction surface toward the user. Through this surface (GUI) the user has access to all the other resources of netAgora. VSR may be freely adopted to meet the specific requirements of different user categories. There is no theoretical limit to the number of users that may simultaneously be connected to netAgora.

The Virtual Responder (VR) is a system component, which simulate the behaviour of other responders. From the point of view of the player there is no difference between a virtual actor and a real actor. This means that in netAgora there are always several actors, real or virtual ones, which you as user have to coordinate and communicate with.

The Disaster Simulator (DS) is the core of netAgora. DS can calculate (simulate) the dynamic evolution of a set of crucial disaster variables and react on different user decisions and actions. The ability to handle geographical or spatial information (GIS) is a crucial faculty of the Disaster simulator. The user can select a scenario, i.e. disaster, from 
the Scenario Bank (SB) or set up a new one, or change an existing one, with help of the Scenario Editor/Generator (SEG). The Assessment Kit (AK) helps the user to evaluate the decisions and actions taken during the playing of a scenario.

Experiences and Lessons Learned (ELL), at last, is a knowledge bank with tested and verified disaster and crisis knowledge. Via the Meeting and Cooperation Support (MSC) the user can interact and discuss with other disaster responders and via the Expert Panel (EP) she or he can put disaster related questions to a group of disaster experts and disaster researchers.

In short, the main objective of netAgora is to provide, in one place, all the necessary resources and functions for best possible pan European preparation, training, and learning in relation to crisis and complex emergency situations.

Those objectives will be reached by developing the netAgora environment as a training tool and disaster simulator that are: inter active, situation flexible, cross platform, co-creating, computer and net based, based on open source, and usable in different social situations.
In summary, the netAgora project will ensure the future security of European citizens by:

- Rising awareness and preparedness of potential disaster responders by help of the components and resources in the netAgora environment.

- Improving cooperation and coordination between responders, even in different European nations, by help of the netAgora tools.

- Improving competence and performance of organisations involved in security issues.

- Bridging cultural and gender differences between responders from different nations and different backgrounds.

Further, tnetAgora project will improve the competitiveness of the European security industry by:

- Providing tools and methods based on high-end and emerging technologies within information and communication technology (ICT).

- Increasing the competence within simulation and decision support for security applications.

- Opening up an increasing market for supply and support of security related applications.

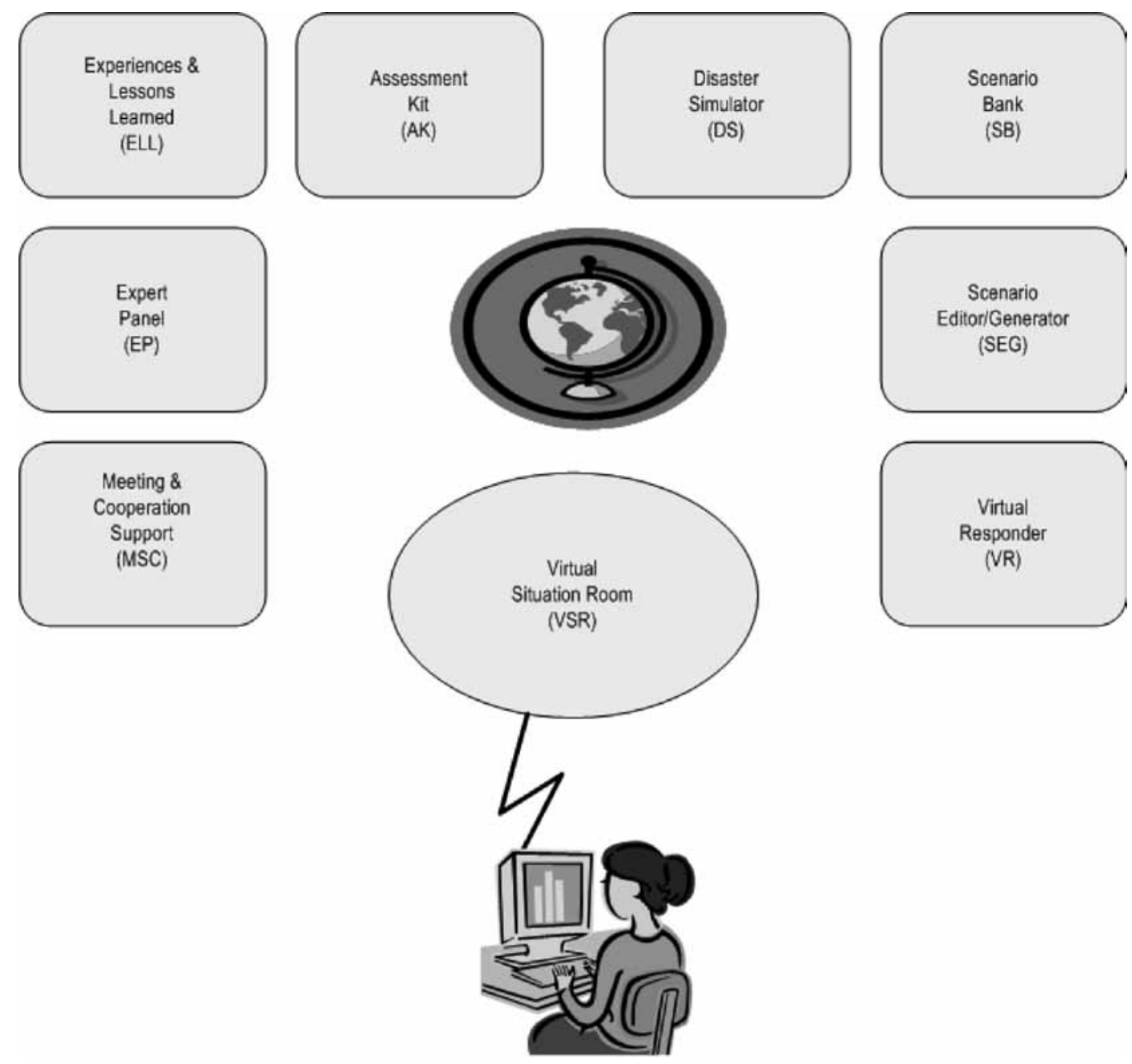

Figure 3: The netAgora environment. 


\section{Scenario creation}

The project departures from two distinct points. Those are first the potential future users of netAgora and their needs, wishes, and requirements. The second departure point is the existing stock of open source tools and development environments. With this launching platform established it is the task of block two to design and construct both a set of test scenarios and the netAgora environment with its disaster simulator and other training tools. With a first version of netAgora environment up and running it will be the task of the last block to have normal users from different user categories to run the disaster simulator and environment with the different test scenarios and to evaluate the outcome of those tests. Those evaluation results will be used in correcting faults and in improving the tools.

The objectives of the development of test scenario and test data retrieval are:

- To create a realistic and dynamic scenario of an international disaster involving a large set of actors representing public, private and non-governmental organisations. The scenario will be based on previous disasters and possible future emergencies.

- To design the scenario so that involved actors are trained in mitigating the disaster through intra- and inter-organizational cooperation including communication failure, conflict and confusion. This will facilitate a learning situation based on network management rather than control and command.

- To retrieve data from previous national and international disasters in Europe, as well as to map the different structures of emergency management in target European countries, to constitute the base for building the scenario.

- To interact in the development of the complex emergency model implementing the scenario in the model.

The creation of emergency situation scenarios is not a trivial task and as it is specific, traditional scenario creation methods are not totally adequate and applicable. Scenario planning is a method to develop scenarios following a structured process (Schoemaker, 1995; Lindgren and Bandhold, 2003; Borglund and Öberg, 2007). The fundamental ideal is to provide a structured way to create a dynamic interaction between the environment and an organization to cover a broad range of future possibilities and future uncertainties and to expand people's thinking (Ellis and Shpielberg, 2003; Schoemaker, 1993; Wack, 1985; Weick and Quinn, 1999). An adjusted model of scenario planning can be a support for creation of emergency situation scenarios. Systems thinking used in conjunction with scenario planning leads to plausible scenario story lines because the causal relationship between factors can be demonstrated.

\subsection{Retrieving test data}

In accordance with the tradition of scenario development the following steps will guide the work: The kind of emergency of interest will be identified and defined, as well as the major stakeholders and/or actors affected and influencing the emergency. Based on these definitions, two to three previous national and/or international disasters will be indentified and described in detail. Focus will be put in involved actors, decision making, cooperation, management communication, position frames and outcome. The emergency management systems planned to be applied in four countries, Greece, Slovenia, Norway and Sweden will be mapped and described in detail to facilitate input to the scenario. Further, expert interviews with key actors will be done to include state of the art insights to future developments of disasters and emergencies in Europe. The development of a plausible scenario depends on the input and in this case it is crucial that realistic organizational structures in the different countries are included.

\subsection{Development and building of scenarios}

Based on the retrieved test data, a realistic scenario will be developed according to state of the art proceedings. Researchers and users will compose a scenario building group. The retrieved data will be analysed and complimented by brainstorming and analytical thinking, e.g. identifying current trends and predetermined elements that will affect factors of interest. A basic scenario will be built where different factors are organized as a matrix or grid to show interlinkages and causal relationships. Thereafter narratives and images will be developed. At this stage, plausibility, consistency and challenge of the scenario will be assessed by focus group interviews with expert and user groups. Last, the scenario will be modified, inconstancies eliminated and tested again until it is usable.

\subsection{Implementing scenario with the emergency model}

The scenario will be converted into the emergency model which means that the teams working with the workpackages will collaborate in translating the scenario to the macro- and microscopic models. The scenario will once again be tested to see if it is consistent and usable.

\section{Validation}

The netAgora design from section four above constitutes our result, or data, so far. At this stage of the project, however, one should note that design has not yet been implemented and field tested. Hence, we here have to limit ourselves to a theoretical validation against published research results.

First, netAgora is an idealized design in the meaning of Ackoff et al. (2006). This means that it is the best solution that the designers can imagine or conceptualize at the time being. Hence, the initial design proposed by the development of NetAgora System plays an important role as a 
source for continuous improvement according to Simon's (1996) principle for constructive critique.

Nyström (2006) has shown that many web applications are used just to a tiny fraction of their full potential. On the other hand, she also finds that if properly designed they may be a source of empowerment and emancipation. By given the users an active role in filling the site with content and by opening up for communication between the users the chances for a well used site seem to increase. Those facilities are provided in netAgora increasing the possibilities for a successful implementation.

\subsection{Living systems theory}

Living Systems Theory (LST) defines twenty critical subsystems or critical functions that are required for guaranteeing sustained life in any living system (Miller, 1978). This makes LST an excellent tool for judging the viability also of artificial systems. Hence, the crucial question here is weather netAgora is viable or not according to LST?

The answer is not entirely evident. First, there is no direct correspondence between the functions of netAgora and all of LST's twenty critical subsystems. Among other things, the eight subsystems handling energy and matter are completely lacking in netAgora. On the other hand, if the human user is taken as part of the netAgora system it per definition becomes a living one. Hence, with the human user included netAgora is a living system with some of its functions supported and enhanced by artificial help systems, or artifacts. So the initial question becomes, in what ways could the artificial part of netAgora provide an even better support?

One requirement that is not explicitly met in the current design is the need to gap cultural and institutional differences between different parts of Europe. LST here has to provide the subsystems decoder and encoder, i.e. the subsystems responsible for translating between internal and external system languages and codes. By explicitly incorporating those functions into the netAgora design the bridging of cultural differences could be handled more effectively.

Further, by adding the subsystem Internal Transducer netAgora would develop into a monitoring, "world watch", system. In this way the link between the internal model world and the external object world would become stronger. This could then be a first step of developing netAgora into a Soft Early Warning System according to ideas put forward by Holmberg (2008).

Geographical information (GIS) is a central component in netAgora. This is fully in line with LST where Miller (1978) points out that three dimensional Euclidean space is the only space common to all concrete living systems. In order to support this finding, Asproth et al. (2006) have already defined guidelines for spatial planning based on anticipatory, fuzzy, and constructivist principles.

\subsection{Critical systems heuristics}

In any systems application you have to draw a system boarder, i.e. to decide what to take into account and what to leave out. The systems approach may help you see better and understand better what fall within the system border but at the same time it makes you blind for what falls outside of that boarder. The location of the system border, however, is seldom obvious. In most cases there are numerous alternatives at hand. Each giving most different output or result of the systemic work. As a consequence, deciding on the system border becomes a critical step in all system applications. Critical Systems Heuristics (CSH) (Ulrich, 1994) does not stipulate where to draw the border but it helps you see the consequences of different alternatives.

Table 1: The boundary questions.

\section{SOURCES OF MOTIVATION}

(1) Who is the client? That is, whose interests are served?

(2) What is the purpose? That is, what are the consequences? What is the measure of improvement? That is, how can we determine that the consequences, taken together, constitute an improvement?

\section{SOURCES OF CONTROL}

(4) Who is the decision-maker? That is, who is in a position to change the measure of improvement? (5) What resources are controlled by the decisionmaker? That is, what conditions of success in securing improvement can those involved control? (6) What conditions are part of the decision environment? That is, what conditions lie outside the decision-maker's control?

\section{SOURCES OF KNOWLEDGE}

(7) Who is considered a professional? That is, who is involved as an expert, e.g. as a systems designer, researcher, or consultant?

(8) What expertise is consulted? That is, what counts as relevant knowledge?

(9) What serves as source of guarantee? That is, who or what is assumed to make sure that improvement will be achieved (e.g., consensus among experts, stakeholder participation, the experience of those involved, the methods used, political support)?

\section{SOURCES OF LEGITIMACY}

(10) Who is witness to the interests of those affected but not involved? That is, who voices the concerns of stakeholders who are not involved or cannot speak for themselves, including future generations and non-human nature?

(11) What secures the emancipation of those affected from the premises and promises of those involved? That is, where does legitimacy lie?

(12) What worldview is determining? That is, what visions of "improvement"

are considered, and how are they reconciled? 
Ulrich (1994) has provided a list with twelve boundary questions. With help of those questions it becomes possible to assess the boundary decisions you have made and to compare them with alternative ones. Those questions in slightly modified form are given in table 1 .

The questions in the given form identify the actual border. By changing the verb is/are to ought/should they help you see alternatives, i.e. new things to take into account and old things to let out.

The boundary questions will not be answered here. Instead we invite our readers to apply those questions on the netAgora design in section four. In this way this paper will lead to a third generation design according to Banathy (1996). The vision for this type of design, i.e. that everyone being impacted by a new system also have to take part in its design, may seem too idealistic. Anyhow, as shown by Löfstedt (2008) third generation design may be applied with some degree of success to this type of development projects.

\section{Conclusions}

The insights gained and lessons learned from this initial work is highly preliminary and have to be further verified and refined during successive project steps. Hence, for the time being it is just possible to say that:

- In working with colleagues from all over Europe, it has become clear that security and security preparation activities are highly urgent issues for most, if not all, EU member states. The local conditions, threats, and organisation of crisis management, however, may vary highly from one member state to another one. Those differences, hence, have to be taken care of in any solution approach.

- From our critical review of current research results it has further become evident that preparation and training are the most crucial parts in any system for crisis and disasters management.

- The netAgora design will meet most pan European needs for an integrated learning, training, preparation, and communication environment.

- The realism and trouthfulness of netAgora, however, will be of crucial importance. Hence, great effort has to be put into the work of capturing scenarios and events from the real world and incorporating them into the netAgora tool.

- It has also become evident that disaster situations will change all the time. New threats will emerge and at the same time differences between differents part of EU will remain. Hence, a system for feedback and continuous learning will also be a most important part of the netAgora environment.

- In using Internet and the web as a main veichle for netAgora many practical problems have been solved automatically and the training tool will be available for everyone who needs it, all over Europe.

- The combination of technical and social research competence in the project team has turned out as being of paramount importance.

- A systemic framework like Living Systems Theory and a systemic design method like Idealized Design have been good intellectual tools for this type of Operational Research application.

- Critical Systems Heuristics and principles for third generation design can be applied for continuous improvement of the design.

\section{References}

Ackoff, R. L., Magidson, J., \& Addison H. J. (2006). Idealized Design, Creating an Organizations Future. Upper Saddle River, New Jersey: Wharton School Publishing.

Alvinius, A, Danielsson, E, Kylin, C \& Larsson, G. (2007). Lika lägesbild. Olika situationsförståelse. [Similar position image. Different situation understanding]. (ILM Serie I:34) Försvarshögskolan, Institutionen för ledarskap och management.

Asproth, V. (2007) Organizational Learning in Inter-organizations, In Remenyi, D. (Ed) Proceedings of the 4th International Conference on Intellectual Capital Knowledge Management \& Organisational Learning, pp. 37-44, Stellenbosch, South Africa

Asproth, V., Holmberg, S. C., \& Håkansson, A. (2006). Multi Modal Anticipation in Fuzzy Space. In D. M. Dubois (Ed), Computing Anticipatory Systems, CASYS'05 - Seventh International Conference. Melville, New York: American Institute of Physics, Vol. 839: 442-452.

Asproth, V., Håkansson, A. (2007) Complexity Challenges of critical situations caused by flooding. Emergence: Complexity and Organization, 9(1-2), 34-40.

Asproth, V., Nyström, C. A. (2008) Communication and information exchange among SMEs and their local environment Journal for Organisational Transformation and Social Change, 5(2), 175189, DOI: 10.1386/jots.5.2.175_1.

Banathy, B. H. (1996). Designing Social Systems in a Changing World. London: Plenum.

Boin, R. A., 't Hart, P. (2007). The crisis approach. In Rodrígues, H., Quarantelli, E. L., Dynes, R. R. (Eds.). (2007). Handbook of Disaster Research, pp. 42-54, New York: Springer.

Bolin, B. (2007). Race, Class, Ethnicity, and Disaster Vulnerability. In Rodrígues, H., Quarantelli, E. L., Dynes, R. R. (Eds.). (2007). Handbook of Disaster Research, pp. 113-129, New York: Springer.

Borglund, E. A. M., \& Öberg, L-M. (2007). Scenario Planning And Personas as Aid to Reduce Uncertainty of Future Users. In the proceedings of IRIS 30, 11-14 August, Tampere.

Burt, G. \& Chermack, T. J. (2008). Learning with scenarios: Summary and critical issues. Advances in Developing Human Resources, 10(2), 285-295, DOI: 10.1177/1523422307313334 .

Caruson, K. \& MacManus, S. A. (2008). Disaster vulnarabilities. How strong a push towards regionalism and intergovernmental cooperation? The American Review of Public Administration, 38(3) 286- 306, DOI: 10.1177/0275074007309152.

Danielsson, D, Alvinius, A, Kylin, C \& Larsson, G. (2007). Ledarskap och beslutsfattande vid komplexa olyckor och kriser - En sammanfattande rapport. [Leadership and decision-making at complex accidents and crises - A concluding report]. (ILM Serie I:37) Försvarshögskolan, Institutionen för ledarskap och management.

Drabek, T. E., McEntire, D. A. (2002). Emergent phenomena and multiorganizationl coordination in disasters. lessons fron the research literture. International Journal of Mass Emergencies and Disasters, 20, 197-224.

Drabek, T. E. (2007). Community Processes: Coordination. In Rodrígues, H., Quarantelli, E. L., Dynes, R. R. (Eds.). (2007). 
Handbook of Disaster Research, pp. 217-233, New York: Springer.

Dubois, D. M. \& Holmberg, S. C. (2008). Self-Adapting Parameters in Simulating of Management Systems. In R. Trappel (Ed), Cybernetics and Systems 2008. Vienna: Austrian Society for Cybernetic Studies, Vol 1: 26-31.

Dynes, R. R. (1970). Organized behaviour in disaster. Lexington, MA: Heath Lexington Books.

Ellis, S., \& Shpielberg, N. (2003). Organizational learning mechanisms and managers' perceived uncertainty. Human Relations, 56 (10), 1233-1254, DOI: 10.1177/00187267035610004.

Ekker, K., \& Eidsmo, A. (2006). Evaluation of software used in an internet-based simulation: Are there any cultural differences? Proceedings of the IADIS Virtual Multi Conference on Computer Science and Information Systems, IADIS Press.

Fearn-Banks, K. (2002). Crisis Communication. A Casebook Approach. Mahwah: Lawrence Erlbaum Ass.

Gordon, H. J. (2008). Integrating learning into safety. Developing a robust lessons-learned program. Professional Safety, September 2008, 30-33.

Holmberg, S. C. (2000). Designing and Prototyping Towards Anticipatory Applications. In D. M. Dubois (Ed), Computing Anticipatory Systems, CASYS'99 - Third International Conference. Melville, New York: American Institute of Physics, Vol 517: 31-41.

Holmberg, S. C. (2001). OR 2000: Challenges and Prescriptions for the New Millennium. In G. Ragsdell \& J. Wilby (Eds), Understanding Complexity. London: Kluwer Academic / Plenum Publishers, pp $257-268$.

Holmberg, S. C. (2008). A New Era for Living Systems Theory. In R. Trappel (Ed), Cybernetics and Systems 2008. Vienna: Austrian Society for Cybernetic Studies, Vol 1: 179 - 184.

Kendra, J. M. \& Wachtendorf, T. (2006). Improvisation, Creativity and the Art of Emergency Management ' in Disaster Research Center Preliminary Paper \#357. Published: University of Delaware Kreps, G. A. (1989). Social Structure and Disaster. Newark, London, and Toronto: University of Delaware and Associated University Presses.

Keys, P. (1991). Operational Research and Systems, The Systemic Nature of Operational Research. London: Plenum Press.

Kljajić Borštnar, M., Škraba, A., Rajkovič, V. \& Kljajić, M. (2007). Simulation based group learning. Organizacija, 40(6), 239-247.

Leleur, S. (2005). Systemic Planning, Principles and Methodology for Planning in a Complex World. Lyngby: Polyteknisk Forlag.

Lindgren, M., \& Bandhold, H. (2003). Scenario planning: The link between future and strategy. Basingstoke, Hampshire: Palgrave Macmillan.

Löfstedt, U. (2008). e-Services for and by Citizens. Östersund: Department of Information Technology and Media, Mid Sweden University.

McEntire, S. A. (2007). Local Emergency Management Organization. In Rodrígues, H., Quarantelli, E. L., Dynes, R. R. (Eds.). (2007). Handbook of Disaster Research, pp. 168-182, New York: Springer.

Miller, J. G. (1978). Living Systems. New York: McGraw-Hill.

Mingers, J. \& Gill, A. (Eds) (1997). Multimethodology. Chichester: Wiley.

Nyström, C. (2006). Designing Intranets for Viability, Approaching Organizational Empowerment and Participation. Umeå: Department of Informatics, Umeå University.

Olofsson, A. (2007). Crisis communication in multicultural societies: A study of municipalities in Sweden. International Journal of Mass Emergencies and Disasters, 25 (2) 145-172.
Olofsson, A., Öhman, S \& Rashid, S. (2006). Attitudes to gene technology. The importance of trust in institutions. European Societies, 8(4) 601-624, DOI: 10.1080/14616690601002707.

Perrow, C. (1999 [1984]). Normal accidents. Living with high-risk technologies. Princeton: Princeton University Press.

Poteyeva, M., Denver, M., Barsky, L. E., Aguirre, B. E. (2007). Search and Rescue Activities in Disasters. In Rodrígues, H., Quarantelli, E. L., Dynes, R. R. (Eds.). (2007). Handbook of Disaster Research, pp. 200-216, New York: Springer.

Quarantelli, E. L. (1988). Disaster crisis management: A summary of research findings. Journal of Management Studies, 25(4), pp. 373-385, DOI: 10.1111/j.1467-6486.1988.tb00043.x .

Quarantelli, E. L., Lagadec, P., Boin, R. A. (2007). A Heuristic Approach to Future Disasters and Crises: New, Old, and In-Between Types. In Rodrígues, H., Quarantelli, E. L., Dynes, R. R. (Eds.). (2007). Handbook of Disaster Research, pp. 16-41, New York: Springer.

Quarantelli, E.L. (2006) The disasters of the $21^{\text {st }}$ century: A mixture of new, old, and mixed types. Preliminary paper \#353. Disaster Research Center (DRC). University of Delaware.

Quarantelli, E. L. (2000). Disaster Research. In Borgatta, E., Montgomery, R. (Eds.). (2000). Encyklopedia of Sociology, pp. 682-688. New York: Macmillan.

Rodrígues, H, Quarantelli, E. L. \& Dynes, R. R. (Eds) (2006). Handbook of disaster research. New York: Springer.

Santos, G \& Aguirre, B. E. (2004). A critical review of emergency evacuation simulation models. Preliminary paper \#339. Disaster Research Center (DRC). University of Delaware.

Schoemaker, P. J. H. (1993). Multiple scenario development: Its conceptual and behavioral foundation. Strategic Management Journal, 14(3), 193-213, DOI: 10.1002/smj.4250140304.

Schoemaker, P. J. H. (1995). Scenario planning: A tool for strategic thinking. Sloan Management Review, 36(2), 25-40.

Simon, H. A. (1996). The Science of the Artificial, Third Edition. Cambridge, Massachusetts: MIT Press

Stallings, R. A., Quarantelli, E. L. (1985). Emergent citizen groups and emergent management. Public Administration Review, 45, 93-100.

Sundelius, B, Stern, E and Bynander, F. (2001). Krishantering på svenska - teori och praktik. [Crisis Management in Swedish Theory and Practice].Stockholm: Santérus förlag.

Ulrich, W. (1994). Critical Heuristics of Social Planning, A New Approach to Practical Philosophy. Chichester: Wiley.

Wachtendorf, T \& Kendra, J. (2005). Improvising Disaster in the City of Jazz: Organizational Response to Hurricane Katrina. Understanding Katrina: Perspectives from the Social Sciences. Social Science Research Council. http://understandingkatrina. ssrc.org

Warfield, J. N. (1990). A Science of Generic Design, Managing Complexity Through Systems Design. Salinas, CA: Intersystems Publications.

Wack, P. (1985). Scenarios uncharted waters ahead. Harvard Business Review, September-October, 73-89.

Weick, K. E. (1988). Enacted Sensemaking in Crisis Situation. Journal of Management Studies, 25(4) 305-317, DOI: 10.1111/j.1467-6486.1988.tb00039.x.

Weick, K. E. (2005). Organizing and the Process of Sensemaking. Organization Science, 16(4), 409-421, DOI: 10.1287/ orsc.1050.0133.

Weick, K. E., \& Quinn, R. E. (1999). Organizational change and development. Annual Review Psychology 50, 361-386, DOI: 10.1146/annurev.psych.50.1.361.

Viveca Asproth received the doctor $(\mathrm{PhD})$ and the reader (Docent) degrees from the University of Stockholm. 
Currently she is professor in informatics at Mid Sweden University in Östersund, Sweden. Main reaserch interests include visualization, spatial systems, decision support, anticipation and fuzzy systems.

Stig C Holmberg holds a Msc and a PhD in Engineering from The Royal Institute of Technology, Stockholm. He is a former president of the Swedish Association for Operational Research and is currently professor in informatics at Mid
Sweden University. Main research interests include modelling and simulation of anticipatory and spatial systems.

Ulrica Löfstedt holds a Msc and a PhD in Computer and Systems Sciences from Mid Sweden University, Östersund. She is a Senior Lecturer in Informatics at Mid Sweden University. Her main research interests include e-Government services and e-Participation and also technical communication. 